\title{
Assessment of uncertainties in greenhouse gas emission profiles of livestock sectors in Africa, Latin America and Europe
}

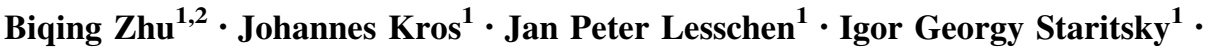 \\ Wim de Vries $^{3}$
}

Received: 14 April 2015/Accepted: 4 November 2015/Published online: 12 December 2015

(C) The Author(s) 2015. This article is published with open access at Springerlink.com

\begin{abstract}
The global animal food chain has a large contribution to the global anthropogenic greenhouse gas (GHG) emissions, but its share and sources vary highly across the world. However, the assessment of GHG emissions from livestock production is subject to various uncertainties, which have not yet been well quantified at large spatial scale. We assessed the uncertainties in the relations between animal production (milk, meat, egg) and the $\mathrm{CO}_{2}, \mathrm{CH}_{4}$, and $\mathrm{N}_{2} \mathrm{O}$ emissions in Africa, Latin America and the European Union, using the MITERRA-Global model. The uncertainties in model inputs were derived from time series of statistical data, literature review or expert knowledge. These model inputs and parameters were further divided into nine groups based on type of data and affected greenhouse gas. The final model output uncertainty and the uncertainty contribution of each group of model inputs to the uncertainty were quantified using a Monte Carlo approach, taking into account their spatial and cross-correlation. GHG emissions and their uncertainties were determined per livestock sector, per product and per
\end{abstract}

Electronic supplementary material The online version of this article (doi:10.1007/s10113-015-0896-9) contains supplementary material, which is available to authorized users.

Johannes Kros

hans.kros@wur.nl

1 Alterra Wageningen UR, P.O. Box 47, 6700 AA Wageningen, The Netherlands

2 Present Address: Institute of Biogeochemistry and Pollutant Dynamics, ETH Zürich, Universitätstrasse 16, 8092 Zurich, Switzerland

3 Environmental Systems Analysis Group, Wageningen University, P.O. Box 47, 6700 AA Wageningen, The Netherlands emission source category. Results show large variation in the GHG emissions and their uncertainties for different continents, livestock sectors products or source categories. The uncertainty of total GHG emissions from livestock sectors is higher in Africa and Latin America than in the European Union. The uncertainty of $\mathrm{CH}_{4}$ emission is lower than that for $\mathrm{N}_{2} \mathrm{O}$ and $\mathrm{CO}_{2}$. Livestock parameters, $\mathrm{CH}_{4}$ emission factors and $\mathrm{N}$ emission factors contribute most to the uncertainty in the total model output. The reliability of GHG emissions from livestock sectors is relatively high (low uncertainty) at continental level, but could be lower at country level.

Keywords Livestock $\cdot \mathrm{N}_{2} \mathrm{O} \cdot \mathrm{CH}_{4} \cdot$ Uncertainty analysis · Global assessment modelling $\cdot$ Monte Carlo simulation

\section{Introduction}

Increasing global animal production is an important cause of various environmental problems (Delgado et al. 1999; Smil 2002; Steinfeld et al. 2006; Galloway et al. 2007). Expanding livestock sectors can contribute to greenhouse gas (GHG) emissions, agricultural land expansion and associated deforestation (Steinfeld et al. 2006), surface water eutrophication (Seitzinger et al. 2005; Boyer et al. 2006), decrease in terrestrial biodiversity (Dise et al. 2011) and nutrient imbalances (Smaling et al. 2008; Menzi et al. 2010). The global animal food chain, including land use change, contributes $14.5 \%$ of the global anthropogenic GHG emissions, including carbon dioxide $\left(\mathrm{CO}_{2}\right)$, methane $\left(\mathrm{CH}_{4}\right)$ and nitrous oxide $\left(\mathrm{N}_{2} \mathrm{O}\right)$, expressed in $\mathrm{CO}_{2}$ equivalents $\left(\mathrm{CO}_{2}\right.$-eq; Gerber et al. 2013). The contribution of livestock production to global anthropogenic GHG emissions varies highly across the world (Gerber et al. 2013). In 
2005 Latin America and the Caribbean have the highest level of GHG emissions from livestock chains (almost 1.3 Gton $\mathrm{CO}_{2}$-eq per year), while Eastern Europe and Russian Federation had the lowest level of emissions ( $>0.2$ Gton $\mathrm{CO}_{2}$-eq per year; Gerber et al. 2013). Cattle is the main contributor $(65 \%)$ to the global livestock sector's GHG emissions, while pigs, poultry, buffaloes and small ruminants have much lower emission levels, each representing between 7 and $10 \%$ of total livestock emissions. The bulk of the GHG emissions originate from four main categories of processes: $\mathrm{CH}_{4}$ emissions from enteric fermentation, $\mathrm{CH}_{4}$ and $\mathrm{N}_{2} \mathrm{O}$ emissions from manure management, $\mathrm{CO}_{2}$ and $\mathrm{N}_{2} \mathrm{O}$ emissions from feed production, processing and transport, and $\mathrm{CO}_{2}$ emissions from energy consumption (Gerber et al. 2013).

The Intergovernmental Panel on Climate Change (IPCC) provides guidelines for calculating GHG emissions from various inventories, using various default emission factors (EFs) for $\mathrm{CO}_{2}, \mathrm{~N}_{2} \mathrm{O}$ and $\mathrm{CH}_{4}$ emissions from different sources (IPCC 2006). GHG emissions models of livestock sectors are well established in the literature (De Vries and De Boer 2010; Kros et al. 2012; Bellarby et al. 2013). There are two main types of models that have been developed: process-based dynamic models (IPCC Tier 3 approach), e.g. the Dutch model for enteric fermentation (Bannink et al. 2011) and empirically based (usually emission factor based) models (Tier 1 or 2 approach), e.g. CAPRI (Weiss and Leip 2012) or MITERRA-Europe (Lesschen et al. 2011).

To our knowledge, no studies have yet been performed to assess the uncertainties in the GHG emission profiles of livestock at continental scale. Only research focussing on one sector and/or on agriculture in general has been executed so far. Examples are the quantification of uncertainties in: (1) soil $\mathrm{N}_{2} \mathrm{O}$ emissions from croplands in the USA, using the process-based DAYCENT model (Del Grosso et al. 2010), (2) total emissions of $\mathrm{N}_{2} \mathrm{O}$ for the European Union and its member states, using the empirical INTEGRATOR model (Kros et al. 2012), (3) $\mathrm{CH}_{4}$ emissions from livestock in Canada, using the IPCC Tier 2 methodology (Karimi-Zindashty et al. 2012) and (4) GHG emissions from dairy cow production systems using a stochastic modelling approach (Zehetmeier et al. 2014). The expected benefit of an improved reliability of estimated GHG emissions, both now and in response to management actions, is likely to enhance actors including governments, sector representatives and farmers to further implement activities to reduce the GHG emissions.

The objective of this research is to assess the GHG emission profiles of livestock sectors and livestock products and their uncertainty at continental scale. We used the MITERRA-Global model (Lesschen et al. 2014), an emission factor (EF)-based model, to assess the uncertainty in $\mathrm{GHG}\left(\mathrm{CO}_{2}, \mathrm{CH}_{4}\right.$, and $\left.\mathrm{N}_{2} \mathrm{O}\right)$ emissions from livestock production at continental scale using a life cycle assessment (LCA). We applied the MITERRA-Global model for three continents, Africa, Latin America and Europe (EU27 ), to represent continents with different socioeconomic status.

\section{Materials and methods}

\section{Calculation of livestock GHG emissions with MITERRA-Global}

MITERRA-Global calculates among others the emissions of the greenhouse gases $\mathrm{CO}_{2}, \mathrm{CH}_{4}, \mathrm{~N}_{2} \mathrm{O}$, in a deterministic and annual basis using emission and leaching factors (Lesschen et al. 2011). The main emission pathways related to livestock production are shown in Fig. 1. MITERRA-Global also calculates emissions of gaseous $\mathrm{NH}_{3}$ and $\mathrm{NO}_{x}$ and $\mathrm{NO}_{3}$ leaching to groundwater and $\mathrm{N}$ runoff to surface water. The latter two were not further investigated in this study.

The modelling concept of MITERRA-Global is similar to the MITERRA-Europe model (Velthof et al. 2009; Lesschen et al. 2011), but it includes a larger geographic region. Main MITERRA-Global input data include: crop data, livestock data, feed data, fertilizer consumption data and spatial data on land cover, soil and climate. Livestock types included in the assessment are broilers, laying hens, pigs, dairy cows, other cattle, goats and sheep. Besides total GHG emissions per region or per hectare of land, the model also calculates emissions per kilogram product, following a top-down LCA-based approach as described in Lesschen et al. (2011). Calculations are performed at a subnational level (e.g. province level), and the output can be provided at sub-national, national or continental level.

MITERRA-Global accounts for the following $\mathrm{GHG}$ sources: $\mathrm{CH}_{4}$ from enteric fermentation, $\mathrm{CH}_{4}$ and $\mathrm{N}_{2} \mathrm{O}$ from manure management, direct and indirect $\mathrm{N}_{2} \mathrm{O}$ soil emissions, $\mathrm{CO}_{2}$ and $\mathrm{N}_{2} \mathrm{O}$ from organic soils, $\mathrm{CO}_{2}$ from lime and urea application, and GHG emissions from fertilizer production and fossil fuel use. All emissions were converted to $\mathrm{CO}_{2}$ equivalents $\left(\mathrm{CO}_{2}\right.$-eq) using the IPCC estimates of 100-year global warming potential (GWP) values, which are 25 and 298 times the GWP of $\mathrm{CO}_{2}$ for $\mathrm{CH}_{4}$ and $\mathrm{N}_{2} \mathrm{O}$, respectively (IPCC 2007). All emissions were calculated by multiplying activities affecting the GHG emissions with emission factors (EFs). $\mathrm{CH}_{4}$ emissions from enteric fermentation were calculated using animal- and continent-specific Tier 1 EFs derived from the IPCC guidelines (IPCC 2006). $\mathrm{CH}_{4}$ emissions from manure management were calculated using region-specific EFs that depend on animal type, mean annual temperature and 


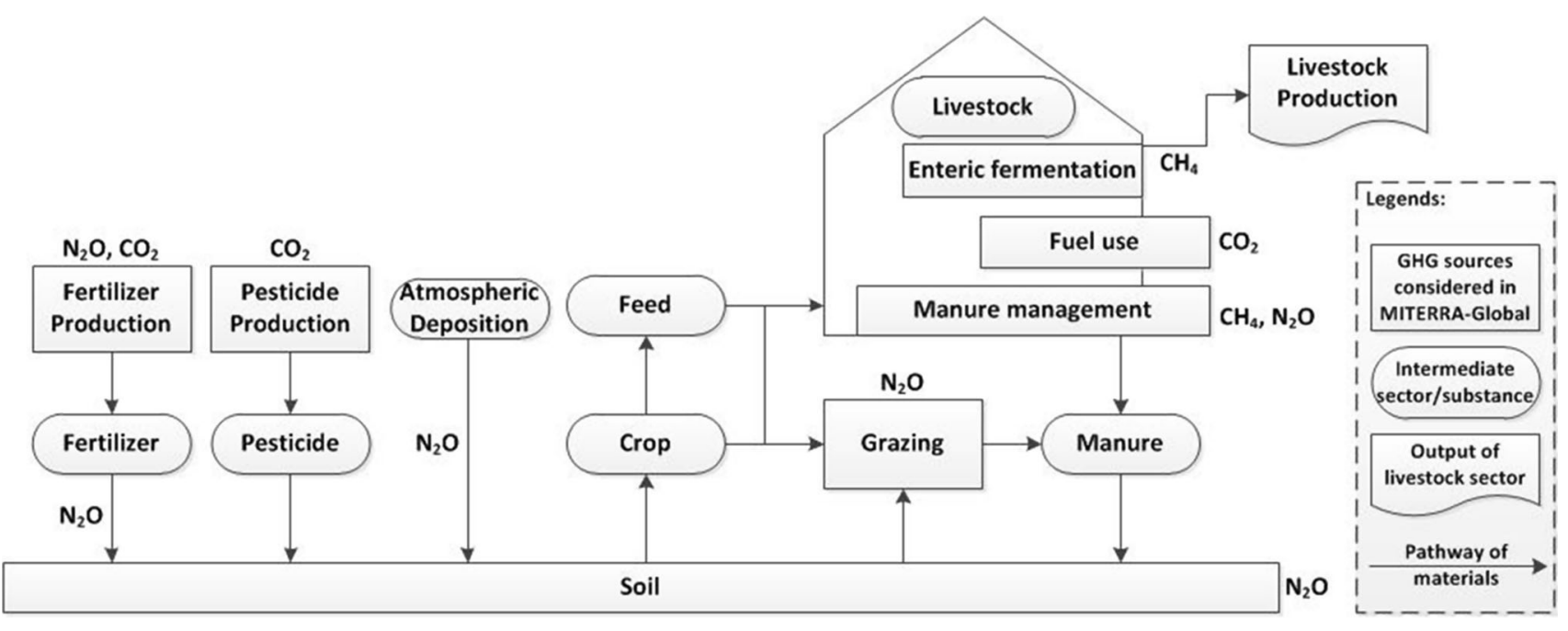

Fig. 1 System boundary and main emission pathways of $\mathrm{CO}_{2}, \mathrm{CH}_{4}$ and $\mathrm{N}_{2} \mathrm{O}$ related to livestock production as included in this study

manure system. The $\mathrm{N}_{2} \mathrm{O}$ emissions from agricultural soils consist of direct and indirect soil emissions. Direct $\mathrm{N}_{2} \mathrm{O}$ emissions were calculated by multiplying $\mathrm{N}$ inputs from application of $\mathrm{N}$ fertilizer and animal manure, crop residues, cultivation of organic soils, and urine and faeces produced during grazing by IPCC (2006) EFs for different $\mathrm{N}$ sources. Indirect $\mathrm{N}_{2} \mathrm{O}$ emissions, related to emissions from $\mathrm{N}$ leaching and runoff and from atmospheric deposition of $\mathrm{N}$ volatilized (mainly $\mathrm{NH}_{3}$ ) from managed soils, were also calculated by multiplying the $N$ fluxes calculated with MITERRA by the IPCC (2006) EFs for those N sources. $\mathrm{CO}_{2}$ emission sources included in our assessment are fuel use for feed production, on farm energy use, fertilizer and pesticide production. $\mathrm{CO}_{2}$ emissions from fuel use and fertilizer production were calculated according to Lesschen et al. (2011). Emissions from on farm energy use were based on Opio et al. (2013) and Macleod et al. (2013), who derived emission factors in terms of emission and/or energy per unit of animal product. $\mathrm{CO}_{2}$ emissions from pesticide use were based on country average pesticide use from FAOSTAT and a general emission factor of $10.97 \mathrm{~kg}$ $\mathrm{CO}_{2}$-eq/kg active ingredient from BioGrace (2011).

\section{Uncertainty quantification of model inputs, parameters and model outputs}

The causes for uncertainty of model outputs can be distinguished in three sources: (1) model input and parameter uncertainty, (2) model structure uncertainty and (3) model solution uncertainty. In the context of MITERRA-Global model, model inputs refer to: (1) activity data, such as animal numbers, crop yields and $N$ fertilizer amounts, and (2) spatial environmental data, such as climate and land use. The model parameters refer to excretion and emission factors. The model solution uncertainty refers to errors caused by rounding, numerical evaluation of integrals, suboptimal optimization solutions, etc. Compared to model input and model structure uncertainty, model solution uncertainty mostly has a marginal contribution to the output uncertainty and has therefore been ignored in this study. The quantification of the uncertainty caused by model structure, however, is not an easy task. A possibility is to compare the results of MITERRA-Global with the results from other models, but this requires the development and application of an independent concurrent model. Another possibility is a comparison with independent data, e.g. based on atmospheric concentration via inverse models (Leip et al. 2011a). Hence, the impact of model input and parameter uncertainty on the uncertainty in GHG emissions is the focus of our study.

We used a Monte Carlo (MC)-based method to analyse the uncertainty of GHG emissions from livestock sectors in Africa, Latin America and Europe as calculated by the MITERRA-Global model. The analysis included uncertainty quantification (UQ) and uncertainty analysis (UA), using a methodology adapted from Kros et al. (2012). The purpose of UQ is to quantify the model output uncertainty in response to input and parameter uncertainty, whereas UA aims to determine how much the uncertainty of individual (groups of) model inputs and/or parameters contributes to the model output uncertainty.

We first selected the model inputs and parameters (MIPs) which directly and/or indirectly influence the GHG emissions. We then performed an uncertainty propagation analyses, using MC simulations to provide uncertainty estimates for the calculated GHG emissions (model output). Since the uncertainty of spatially distributed inputs tend to be spatially correlated, which influences the degree 
to which uncertainties cancel out by spatial aggregation (Heuvelink and Pebesma 1999), both their cross-correlations and spatial correlations between MIPs were taken into account.

Based on the data availability, we identified four different spatial levels, i.e. sub-national, national, continental and generic. The sub-national level is the lowest spatial level used in MITERRA-Global. In Europe, NUTS2 regions were used. In Africa and Latin America, provinces or groups of provinces were used. The boundaries of national level were based on the FAO country definition. For the continental level, we used the IPCC classification of main world regions and continents. Inputs and parameters at generic level remain the same among continents. Ultimately, we selected 89 MIPs (see supplementary material for the full list, Appendix S2) which directly and/or indirectly influence the GHGs emissions $\left(\mathrm{CH}_{4}, \mathrm{~N}_{2} \mathrm{O}\right.$ and $\mathrm{CO}_{2}$ emissions).

\section{Model input and parameter uncertainty quantification}

The uncertainties of the MIPs were represented by probability distribution functions (pdf), further including their spatial correlations (for the same MIP between different spatial locations) and their cross-correlations (between MIPs at the same location). The approach for uncertainty quantification of the MIPs was based on Kros et al. (2012). The full table of uncertainty quantification results is provided in the supplementary material (Appendix S2). The information regarding the pdfs, spatial and cross-correlations of the MIPs was obtained from available statistical data (from FAOSTAT), literature information (when data are not available but published research is available) and expert knowledge (when neither relevant data nor published research is available).

Probability distribution functions The pdfs were described by four parameters: (1) mean $(\mu),(2)$ minimum and maximum values, (3) distribution type and (4) standard deviation $(\sigma)$ or coefficient of variation $(\mathrm{CV})$, i.e. $\sigma / \mu$. For the mean $(\mu)$ of each model input/parameter, we used the default value in the MITERRA-Global database. The Gaussian (normal) distribution is often used to describe the random variation in data. However, many measurements of GHG emissions, especially for $\mathrm{N}_{2} \mathrm{O}$, show a skewed distribution (IPCC 2006). Skewed distributions are particularly common when mean values are low, variances are large, and values cannot be negative (Limpert et al. 2001). Hence, we chose two types of distributions to describe the MIPs: normal distribution and lognormal distribution (for skewed MIPs).

Statistical data from FAO do not provide the associated uncertainty. Here we used the temporal variation in the yearly data as a proxy for the uncertainty, reflecting the random error in data collection and the variance of the true value. Note, however, that this variation not only represents uncertainty, but also the "real" year-to-year variation and/ or long-term trend. Therefore, we estimated the CV from the normalized root mean square error (RMSE) by comparing the observed temporal variation in the yearly statistical data with predicted linear trends in time per country and per category (see supplementary material Appendix S1 for details).

MIPs for which the uncertainties could not be derived from statistical data were estimated on the basis of literature or expert knowledge. The group of MIPs for which uncertainty information was found in literature is summarized in Table 1 . This uncertainty information was usually only expressed as a lower limit ("Min" in Table 1) and an upper limit ("Max" in Table 1).

The CVs or standard deviations (SD) and distribution types for the $\mathrm{N}_{2} \mathrm{O}-\mathrm{N}$ emissions or emissions fractions as derived from IPCC (2006) were all derived from the reported default values and lower and upper limit values. The default was assumed equal to the mean. The deviance of minimum and maximum from the mean showed that the distribution of the $\mathrm{N}_{2} \mathrm{O}-\mathrm{N}$ EFs for $\mathrm{N}$ inputs, atmospheric deposition and grazing were all highly skewed to the left. Therefore, a lognormal distribution was assumed for all these EFs. Taking the interval determined by this minimum and maximum as the $95 \%$ confidence interval $(\mathrm{CI})$, the minimum was regarded as 2.5 percentile and the maximum as 97.5 percentile. For normal distributions $X \sim N\left(\mu, \sigma^{2}\right)$, the $95 \% \mathrm{CI}$ is approximately equal to $(\mu-1.96 \sigma, \mu+1.96 \sigma)$. Thus, on the log scale the difference between the log-transformed maximum and the log-transformed minimum is equal to $2 \times 1.96 \times \sigma$ or $\log ($ Max $)-\log ($ Min $)=2 \times 1.96 \sigma$. Then the SD of this log-transformed distribution was calculated as: $(\log (\operatorname{Max})-\log (\operatorname{Min})) / 2 \times 1.96$. This SD was used as the $\mathrm{CV}$, since a log-transformed SD is approximately equal to a CV on the original scale (Limpert et al. 2001).

Table 2 illustrates the derivation of the uncertainty properties of the $\mathrm{N}_{2} \mathrm{O}-\mathrm{N}$ emissions or emissions fraction based on the mean, minimum and maximum values given in IPCC (2006).

Since for (many) MIPs little information on uncertainties was available, we assigned the $\mathrm{CV}$ of these MIPs using three categories: high uncertainty $(\mathrm{CV}=0.5)$, moderate uncertainty $(\mathrm{CV}=0.25)$ and low uncertainty $(\mathrm{CV}=0.1)$ following Kros et al. (2012). Low uncertainty was used for MIPs derived from good-quality statistical databases; high uncertainty was used for MIPs based on expert knowledge or derived from model estimates; moderate uncertainty was used for all remaining MIPs.

Cross-correlation Cross-correlations were defined by cross-correlation coefficients for related MIPs (Kros et al. 2012). The cross-correlation between $\operatorname{MIP}_{i}$ and $\mathrm{MIP}_{j}$, at the 
Table 1 Uncertainties of emission fractions (EFs) as derived from literature

\begin{tabular}{|c|c|c|c|c|c|c|}
\hline Emission fractions & References & $\mathrm{CV}$ & SD & $\begin{array}{l}\text { Distribution } \\
\text { type }\end{array}$ & Min & Max \\
\hline $\mathrm{N}_{2} \mathrm{O}-\mathrm{N} \mathrm{EF}^{\mathrm{a}}$ for manure management & $\begin{array}{l}\text { (Flugsrud and Hoem } \\
\text { 2011) }\end{array}$ & & 0.35 & Lognormal & 0 & 0.5 \\
\hline $\mathrm{CO}_{2} \mathrm{EF}$ for gasoil & $\begin{array}{l}\text { (Flugsrud and Hoem } \\
\text { 2011) }\end{array}$ & 0.03 & & Normal & 0 & 5 \\
\hline $\mathrm{CH}_{4} \mathrm{EF}$ for manure management & $\begin{array}{l}\text { (Flugsrud and Hoem } \\
\text { 2011) }\end{array}$ & 0.25 & & Normal & 0 & 250 \\
\hline $\mathrm{CH}_{4} \mathrm{EF}$ for enteric fermentation of cattle and sheep & $\begin{array}{l}\text { (Flugsrud and Hoem } \\
\text { 2011) }\end{array}$ & 0.25 & & Normal & 0 & 250 \\
\hline $\mathrm{CH}_{4} \mathrm{EF}$ for enteric fermentation of other animals & $\begin{array}{l}\text { (Flugsrud and Hoem } \\
\text { 2011) }\end{array}$ & 0.40 & & Normal & 0 & 150 \\
\hline NH3-N EF from soils for fertilizer application & (Monni et al. 2004) & 0.30 & & Normal & 0 & 0.5 \\
\hline $\mathrm{N}_{2} \mathrm{O}-\mathrm{N}$ EF for indirect emissions from leaching and runoff (EF5) & (Monni et al. 2004) & & 0.50 & Lognormal & 0 & 0.5 \\
\hline $\mathrm{N}_{2} \mathrm{O}-\mathrm{N}$ EF for emissions from $\mathrm{N}$ inputs (EF1) & (IPCC 2006) & & 0.28 & Lognormal & 0 & 0.5 \\
\hline $\mathrm{N}_{2} \mathrm{O}-\mathrm{N}$ emission from histosols per ha (EF2) & (IPCC 2006) & & 0.63 & Lognormal & 0 & 50 \\
\hline $\begin{array}{l}\mathrm{N}_{2} \mathrm{O}-\mathrm{N} \text { EF for emissions from atmospheric deposition of } \mathrm{N} \text { on soils } \\
\text { (EF4) }\end{array}$ & (IPCC 2006) & & 0.82 & Lognormal & 0 & 0.5 \\
\hline $\mathrm{N}_{2} \mathrm{O}-\mathrm{N}$ EF for grazing & (IPCC 2006) & & 0.57 & Lognormal & 0 & 0.57 \\
\hline
\end{tabular}

${ }^{\text {a }} E F$ stands for emission factor

Table 2 Uncertainty properties in $\mathrm{N}_{2} \mathrm{O}-\mathrm{N}$ emissions or emissions fraction derived from IPCC 2006 guidelines (IPCC 2006)

\begin{tabular}{|c|c|c|c|c|c|c|c|}
\hline \multirow[t]{2}{*}{ Emission fractions } & \multicolumn{3}{|c|}{ Information provided by IPCC } & \multicolumn{4}{|c|}{ Log-transformed properties } \\
\hline & IPCC min & IPCC mean & IPCC max & Mean & Min & $\operatorname{Max}$ & $\mathrm{SD}$ \\
\hline $\mathrm{N}_{2} \mathrm{O}-\mathrm{N}$ EF for $\mathrm{N}$ inputs (EF1) & 0.003 & 0.01 & 0.03 & -4.61 & -5.81 & -3.51 & 0.28 \\
\hline Emission from histosols per ha (EF2) & 2 & 8 & 24 & 2.08 & 0.69 & 3.18 & 0.63 \\
\hline $\mathrm{N}_{2} \mathrm{O}-\mathrm{N}$ EF for atmospheric deposition (EF4). & 0.002 & 0.01 & 0.05 & -4.61 & -6.21 & -3.00 & 0.82 \\
\hline $\mathrm{N}_{2} \mathrm{O}-\mathrm{N}$ EF for grazing & 0.007 & 0.02 & 0.06 & -3.91 & -4.96 & -2.81 & 0.57 \\
\hline
\end{tabular}

same location, denoted as $\rho_{\mathrm{cc}(i, j)}$, was obtained from FAO statistics, literature or expert knowledge. The pairs of MIPs were grouped according to the method used to obtain the cross-correlation coefficient $\rho_{\mathrm{cc}(i, j)}$ and are listed in Table 3. The cross-correlation pairs were selected based on previous research, census data and expert knowledge.

Spatial correlation Given the limited availability of data on spatial correlations, these correlations have been included in a pragmatic way as used by Lesschen et al. (2007) and Kros et al. (2012). For the sub-national level, we assumed that within each sub-national region, the spatial correlation equals 1 . This implies that a given MIP has a generic variance $\left(\sigma^{2}\right)$ within the sub-national region. For each MIP, spatial correlation coefficients were set between spatial units at different spatial levels: sub-national regions within the same country $\left(\rho_{\text {sub-national }}\right)$, countries within the same continent ( $\left.\rho_{\text {national }}\right)$ and continents within the world $\left(\rho_{\text {continental }}\right)$.
Depending on the spatial dependence of the MIP, the spatial correlation coefficients were classified into one of the five assigned levels, following Kros et al. (2012): perfect spatial correlation $(\rho=1)$, high spatial correlation $(\rho=0.8)$, moderate spatial correlation $(\rho=0.5)$, low spatial correlation $(\rho=0.2)$ and no spatial correlation $(\rho=0)$.

\section{Model output uncertainty quantification}

The considered uncertain model outputs are $\mathrm{CH}_{4}, \mathrm{~N}_{2} \mathrm{O}$ and $\mathrm{CO}_{2}$ emissions from livestock sectors in Africa, Latin America and Europe. The GHG emissions include total emissions from the aforementioned continents, and emissions at product level and sector level. The products include cattle meat, cow milk, eggs, pig meat, poultry meat, sheep and goat meat, and sheep and goat milk. The sectors included broilers, laying hens, dairy cows, other cattle, pigs, sheep and goats. GHG emissions and 
Table 3 MIPs for which cross-correlations are considered

\begin{tabular}{|c|c|c|c|}
\hline $\mathrm{MIP}_{i}$ & $\mathrm{MIP}_{j}$ & $\rho_{\mathrm{cc}(i, j)}$ & Information source \\
\hline Animal production data (mostly expressed in tonnes) & Livestock number per country & 0.9 & FAO statistics \\
\hline Area harvested for wheat & Wheat production per country & 0.81 & FAO statistics \\
\hline Area harvested for maize & Maize production per country & 0.81 & FAO statistics \\
\hline Area harvested for soybean & Soybean production per country & 0.81 & FAO statistics \\
\hline Area harvested for barley & Barley production per country & 0.81 & FAO statistics \\
\hline Area harvested for other crops & Other crop production per country & 0.81 & FAO statistics \\
\hline $\mathrm{CH}_{4} \mathrm{EF}$ for manure management & Temperature & 0.5 & Expert knowledge \\
\hline Land areas (FAOSTAT) & Area of land cover types (GIS map) & 0.5 & Expert knowledge \\
\hline $\mathrm{N}_{2} \mathrm{O}-\mathrm{N}$ emission factor for manure management & $\mathrm{N}_{2}$ emission factor from manure management & -0.2 & Expert knowledge \\
\hline NOx emission factor from manure management & $\mathrm{N}_{2} \mathrm{O}-\mathrm{N}$ emission factor for manure management & 0.8 & Expert knowledge \\
\hline Fraction of $\mathrm{N}$ of gross mineralization available on grass & Fraction of $\mathrm{N}$ of gross mineralization on arable land & 0.5 & Expert knowledge \\
\hline
\end{tabular}

uncertainties from other livestock sectors (other poultry, horses, camels, turkeys and other animals) have been calculated and are included in the totals, but results for these livestock sectors are not presented in this paper. In quantifying the uncertainty, we distinguished various, IPCC based, sources for $\mathrm{CH}_{4}, \mathrm{~N}_{2} \mathrm{O}$ and $\mathrm{CO}_{2}$ emissions. The sources for $\mathrm{CH}_{4}$ emission included: enteric fermentation and manure management; for $\mathrm{N}_{2} \mathrm{O}$ emission: direct and indirect soil emission from feed crops, direct and indirect soil emission related to by-product feeds (e.g. soybean cake), manure management, grazing, and fertilizer production; and for $\mathrm{CO}_{2}$ : fuel use, pesticide use, fertilizer production and energy use.

The MC approach was used to generate 1000 multiple realizations of MIPs sampled from their pdfs while taking the spatial and cross-correlation into account. Subsequently, the model was run repeatedly to generate model outputs with multiple input realizations, at the model-required scales. The realizations were generated with the statistical software environment R (R Project for Statistical Computing, http://www.r-project.org/).

\section{Uncertainty analysis}

To quantify the uncertainty contribution of a group of MIPs to the uncertainty in GHG emissions (the model output), we performed a second MC experiment in which the MIPs were grouped into nine groups (Table 4), with no correlation between MIPs across different groups. We started this experiment with $200 \mathrm{MC}$ simulations similar to the uncertainty quantification. Subsequently, $200 \mathrm{MC}$ simulations were performed for each group, in which only one out of the nine groups was randomized. The other eight groups remained constant (using the default value stored in the MITERRA-Global database). The variance from the first 200 runs, $\operatorname{Var}_{\text {all }}$, was used as the reference to calculate the relative contribution of each group to the overall variance in the model outputs. The relative contribution of each MIP group to model output uncertainty was expressed as percentage contribution of the variance of a group to the overall variance $\left(\mathrm{PVAR}_{\text {group }}\right)$ :

PVAR $_{\text {group }}=\left(\right.$ Var $\left._{\text {group }} / \operatorname{Var}_{\text {all }}\right) \times 100 \%$

Table 4 MIPs clustered to nine groups

\begin{tabular}{lll}
\hline Code & Description & Main MIPs (see Appendix S2 for complete overview for all MIPs) \\
\hline LAD & Livestock activity data & Livestock numbers and production \\
CAD & Crop activity data & Crop areas and production \\
OAD & Other activity data & Fertilizer consumption, pesticides, etc. \\
BFD & Biophysical data & Climate, soil data \\
EFC & $\mathrm{CH}_{4}$ emission factors & EF manure management and enteric fermentation \\
EFN & $\mathrm{N}$ emission factors & All N emission factors (including leaching and runoff) \\
LPA & Livestock parameters & $\mathrm{N}$ excretion, manure system usage \\
CPA & Crop parameters & $\mathrm{N}$ content, N index, etc., grass correction \\
OPA & Other emission factors and parameters & $\mathrm{CO}_{2}$ emission factors, fertilizer composition \\
\hline
\end{tabular}


Table 5 GHG emissions (in Mton $\mathrm{CO}_{2}$-eq) and the uncertainty (expressed in terms of $\mathrm{CV}$ ) from livestock sectors per continent

\begin{tabular}{|c|c|c|c|c|c|c|c|c|}
\hline \multirow[t]{2}{*}{ Continent } & \multicolumn{4}{|c|}{ Mean (Mton $\mathrm{CO}_{2}$-eq) } & \multicolumn{4}{|l|}{$\mathrm{CV}$} \\
\hline & Total & $\mathrm{CH}_{4}$ & $\mathrm{~N}_{2} \mathrm{O}$ & $\mathrm{CO}_{2}$ & Total & $\mathrm{CH}_{4}$ & $\mathrm{~N}_{2} \mathrm{O}$ & $\mathrm{CO}_{2}$ \\
\hline Africa & 560 & 352 & 204 & 5 & 0.18 & 0.17 & 0.37 & 0.35 \\
\hline Latin America & 916 & 626 & 275 & 15 & 0.17 & 0.20 & 0.35 & 0.35 \\
\hline EU-27 & 398 & 235 & 130 & 34 & 0.12 & 0.16 & 0.22 & 0.26 \\
\hline
\end{tabular}

Table 6 GHG emissions (in $\mathrm{kg}$ $\mathrm{CO}_{2}$-eq/kg product) and the uncertainty (expressed in terms of $\mathrm{CV}$ ) from livestock products per continent

\begin{tabular}{|c|c|c|c|c|c|c|c|c|c|}
\hline \multirow[t]{2}{*}{ Continent } & \multirow[t]{2}{*}{ Product } & \multicolumn{4}{|c|}{ Emission $\left(\mathrm{kg} \mathrm{CO}_{2}-\mathrm{eq} / \mathrm{kg}\right)$} & \multicolumn{4}{|l|}{$\mathrm{CV}$} \\
\hline & & Total & $\mathrm{CH}_{4}$ & $\mathrm{~N}_{2} \mathrm{O}$ & $\mathrm{CO}_{2}$ & Total & $\mathrm{CH}_{4}$ & $\mathrm{~N}_{2} \mathrm{O}$ & $\mathrm{CO}_{2}$ \\
\hline \multirow[t]{7}{*}{ Africa } & Beef & 43.73 & 27.73 & 15.85 & 0.15 & 0.19 & 0.20 & 0.40 & 0.39 \\
\hline & Cow milk & 4.25 & 2.48 & 1.67 & 0.09 & 0.18 & 0.20 & 0.33 & 0.38 \\
\hline & Eggs & 0.86 & 0.09 & 0.67 & 0.09 & 0.22 & 0.20 & 0.25 & 0.45 \\
\hline & Pork & 4.39 & 1.25 & 2.87 & 0.27 & 0.21 & 0.19 & 0.29 & 0.45 \\
\hline & Chicken meat & 0.81 & 0.12 & 0.61 & 0.08 & 0.21 & 0.20 & 0.24 & 0.44 \\
\hline & Sheep/goat meat & 32.32 & 20.55 & 11.69 & 0.08 & 0.19 & 0.18 & 0.40 & 0.39 \\
\hline & Sheep/goat milk & 6.59 & 4.20 & 2.38 & 0.02 & 0.19 & 0.18 & 0.40 & 0.37 \\
\hline \multirow[t]{7}{*}{ Latin America } & Beef & 45.48 & 31.84 & 13.06 & 0.57 & 0.18 & 0.21 & 0.38 & 0.38 \\
\hline & Cow milk & 1.45 & 0.98 & 0.42 & 0.05 & 0.17 & 0.21 & 0.31 & 0.35 \\
\hline & Eggs & 0.50 & 0.05 & 0.38 & 0.07 & 0.26 & 0.21 & 0.30 & 0.31 \\
\hline & Pork & 2.02 & 0.69 & 1.23 & 0.09 & 0.19 & 0.19 & 0.29 & 0.31 \\
\hline & Chicken meat & 0.37 & 0.06 & 0.27 & 0.04 & 0.23 & 0.21 & 0.28 & 0.31 \\
\hline & Sheep/goat meat & 49.55 & 29.57 & 19.09 & 0.89 & 0.16 & 0.17 & 0.34 & 0.38 \\
\hline & Sheep/goat milk & 7.63 & 4.49 & 3.00 & 0.15 & 0.17 & 0.18 & 0.36 & 0.39 \\
\hline \multirow[t]{7}{*}{ EU-27 } & Beef & 19.64 & 12.89 & 5.71 & 1.03 & 0.14 & 0.18 & 0.23 & 0.30 \\
\hline & Cow milk & 0.83 & 0.53 & 0.24 & 0.06 & 0.12 & 0.16 & 0.22 & 0.27 \\
\hline & Eggs & 1.13 & 0.04 & 0.77 & 0.32 & 0.21 & 0.19 & 0.23 & 0.25 \\
\hline & Pork & 2.51 & 1.19 & 0.93 & 0.39 & 0.15 & 0.17 & 0.25 & 0.25 \\
\hline & Chicken meat & 1.15 & 0.04 & 0.80 & 0.32 & 0.20 & 0.19 & 0.22 & 0.25 \\
\hline & Sheep/goat meat & 28.07 & 16.48 & 9.83 & 1.75 & 0.14 & 0.19 & 0.22 & 0.27 \\
\hline & Sheep/goat milk & 1.79 & 0.91 & 0.75 & 0.13 & 0.12 & 0.16 & 0.21 & 0.24 \\
\hline
\end{tabular}

For this experiment, 200 runs were sufficient to produce satisfactory results as concluded from some test runs. With an increase in MC runs, the performance improved only slightly, but the time required performing the runs increased dramatically.

\section{Results}

\section{Mean livestock GHG emissions and their uncertainties}

\section{Uncertainties in total emissions}

The overall livestock GHG emissions are highest in Latin America (about 900 Mton $\mathrm{CO}_{2}$-eq) and lowest in Europe (EU-27, about 400 Mton $\mathrm{CO}_{2}$-eq). The uncertainty (expressed in terms of $\mathrm{CV}$ ) ranges from 0.16 to 0.37 for the three greenhouse gases. The $\mathrm{CV}$ increases in the following direction: total $\mathrm{GHG}<\mathrm{CH}_{4}<\mathrm{N}_{2} \mathrm{O}$ and $\mathrm{CO}_{2}$. For the continents, the $\mathrm{CV}$ increases in the following direction: EU-27 < Africa and Latin America (Table 5). For all three continents, the largest contributor to the livestock GHG emissions is $\mathrm{CH}_{4}$, followed by $\mathrm{N}_{2} \mathrm{O}$ and then $\mathrm{CO}_{2}$.

\section{Uncertainties in emissions per livestock product}

The total GHG emission (in $\mathrm{kg} \mathrm{CO}$-eq/ $\mathrm{kg}$ ) of the livestock products is higher in Africa and Latin America than in EU27 (Table 6). The per kilogram product-based GHG emission for sheep and goat meat, cattle meat, and sheep and goat milk is much higher than for other livestock products (pig meat, cow milk, eggs and poultry meat). The uncertainty at continental level ranges from 0.12 to 0.26 in 
Table 7 GHG emissions (in Mton $\mathrm{CO}_{2}$-eq) and the uncertainty (expressed in terms of CV) from IPCC categories per continent

\begin{tabular}{|c|c|c|c|c|c|c|}
\hline \multirow[t]{2}{*}{ Category } & \multicolumn{3}{|c|}{ Mean (Mton $\mathrm{CO}_{2}$-eq) } & \multicolumn{3}{|l|}{$\mathrm{CV}$} \\
\hline & Africa & Latin America & EU-27 & Africa & Latin America & EU-27 \\
\hline Total & 560 & 916 & 398 & 0.18 & 0.17 & 0.12 \\
\hline $\mathrm{CH}_{4}$ from enteric fermentation & 339 & 608 & 191 & 0.18 & 0.21 & 0.18 \\
\hline $\mathrm{CH}_{4}$ from manure management & 13 & 17 & 44 & 0.20 & 0.21 & 0.19 \\
\hline $\mathrm{N}_{2} \mathrm{O}$ from Manure Management & 7 & 11 & 9 & 0.36 & 0.33 & 0.23 \\
\hline $\mathrm{N}_{2} \mathrm{O}$ from grazing & 168 & 181 & 23 & 0.43 & 0.48 & 0.40 \\
\hline $\mathrm{N}_{2} \mathrm{O}$ from soil & 23 & 67 & 74 & 0.51 & 0.38 & 0.32 \\
\hline $\mathrm{N}_{2} \mathrm{O}$ from soil related to by-products & 3 & 5 & 6 & 0.23 & 0.31 & 0.30 \\
\hline $\mathrm{CO}_{2}$ and $\mathrm{N}_{2} \mathrm{O}$ from fertilizer production & 5 & 20 & 35 & 0.51 & 0.45 & 0.41 \\
\hline $\mathrm{CO}_{2}$ from fuel use & 2 & 3 & 15 & 0.34 & 0.32 & 0.22 \\
\hline $\mathrm{CO}_{2}$ from pesticide use & 0 & 2 & 1 & 0.34 & 0.35 & 0.32 \\
\hline
\end{tabular}

terms of CV. Africa and Latin America have higher uncertainties for each livestock product as compared to EU-27. Although there is a clear difference between the mean GHG emissions for different livestock products, the uncertainties in GHG emissions are similar for Africa, with a CV around 0.2. For Latin America, sheep and goat meat, cattle meat, and sheep and goat milk have the highest emission per unit product. The uncertainties for these three livestock products are only slightly lower compared to other products. For the EU the pattern is similar to Latin America, but uncertainties are lower for each livestock product. The products with higher emissions do not have lower uncertainties per product.

$\mathrm{N}_{2} \mathrm{O}$ emissions (expressed in $\mathrm{kg} \mathrm{CO}_{2}$-eq/ $\mathrm{kg}$ ) are generally lower than $\mathrm{CH}_{4}$ emission for each product for each continent. However, the uncertainties of the $\mathrm{N}_{2} \mathrm{O}$ emissions are always higher than for $\mathrm{CH}_{4}$. In Latin America and EU27 , the products with highest $\mathrm{N}_{2} \mathrm{O}$ emission have similar uncertainties compared with other products. In general, the relative uncertainty for $\mathrm{CO}_{2}$ emission is higher for each product for each continent, while the $\mathrm{CO}_{2}$ emissions are much lower.

\section{Uncertainty in emissions for IPCC categories}

The GHG emissions per GHG source category and continent (region) are presented in Table 7. For each category, EU-27 has a lower uncertainty than Africa and Latin America. No clear correlation is found between the amount of emission and the relative uncertainty. The category with the highest emission, $\mathrm{CH}_{4}$ emission from enteric fermentation, does have a relative low uncertainty. However, $\mathrm{N}_{2} \mathrm{O}$ emission from soil and grazing, which are the second and third highest emission sources, have high relative uncertainties.

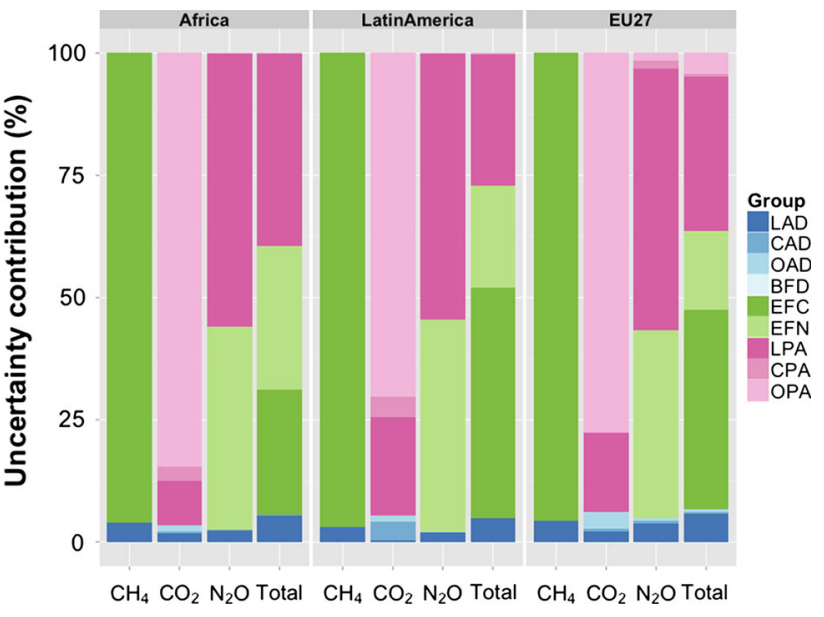

Fig. 2 Uncertainty contribution of different groups of model inputs and parameters (MIPs) to the total greenhouse gas (GHG) emissions from livestock per continent (see Table 4 for the explanation of the used codes)

\section{Contribution of model input and parameter groups on the uncertainty in livestock GHG emissions}

Livestock parameters (LPA), $\mathrm{CH}_{4}$ emission factors (EFC) and $\mathrm{N}$ emission factors (EFN) are the main factors contributing to the uncertainty in total GHG emissions from livestock in Africa, Latin America and Europe (Fig. 2). Livestock activity data (LAD) have a relatively small uncertainty contribution. In Europe, the uncertainty contribution to the total GHG of "other EF and parameters" (OPA) is still about $5 \%$, whereas its contribution to the total uncertainty is almost zero for Africa and Latin America

The uncertainty in $\mathrm{CH}_{4}$ emission is mainly caused by $\mathrm{CH}_{4}$ emission factors (EFC), with a small fraction caused by livestock activity data (LAD). The uncertainty in $\mathrm{N}_{2} \mathrm{O}$ 


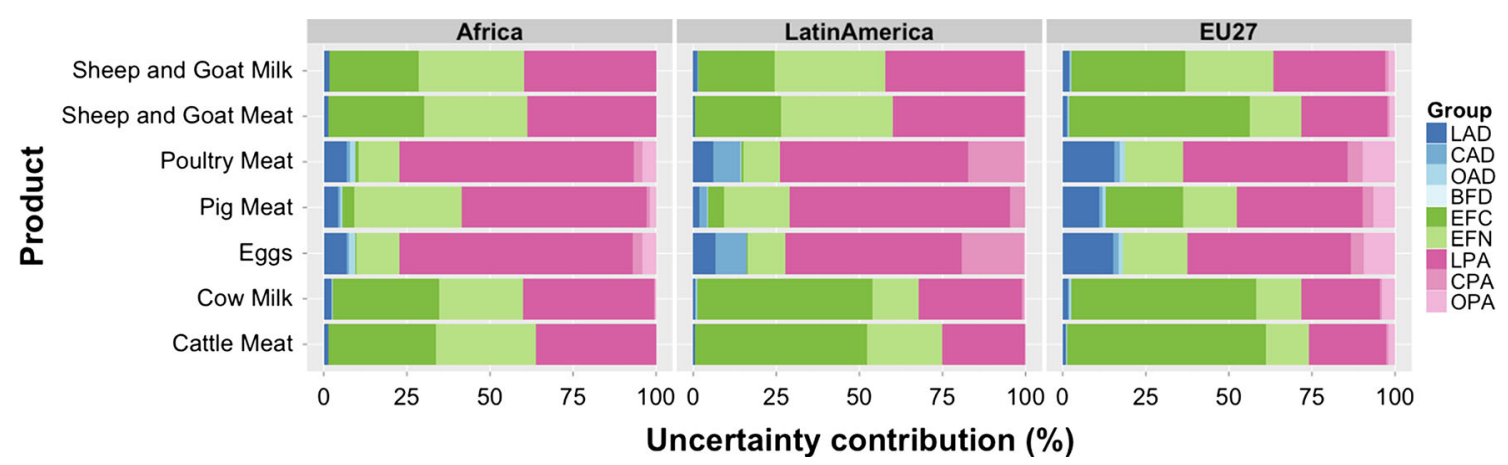

Fig. 3 Uncertainty contribution of different groups of model inputs and parameters (MIPs) to the total greenhouse gas (GHG) emission from different livestock products per continent (see Table 4 for the explanation of the used codes)

emission is mainly caused by $\mathrm{N}$ emission factors (EFN), livestock parameters (LPA) and a small fraction by Livestock activity data (LAD) in Africa and Latin America. In EU-27, other emission factors and parameters (OPA) slightly contribute to the uncertainty in the $\mathrm{N}_{2} \mathrm{O}$ emission. The uncertainty in $\mathrm{CO}_{2}$ emission is mainly caused by other emission factors and parameters (OPA) and livestock parameters (LPA). Crop parameters (CPA) further contribute 10 and $6 \%$ to the uncertainty in $\mathrm{CO}_{2}$ emissions in Africa and Latin America, respectively. However, they do not contribute to the uncertainty of $\mathrm{CO}_{2}$ emissions in EU27.

The uncertainty contribution of groups of MIPs to GHG emissions from livestock products is presented in Fig. 3.

The MIPs that contribute most to the uncertainty of the total GHG emission caused by the production of meat and milk from sheep, goats, cattle or cows are the $\mathrm{CH}_{4}$ emission factors (EFC), livestock parameters (LPA) and $\mathrm{N}$ emission factors (EFN). For poultry meat, pig meat and eggs, the MIPs that contribute most to the uncertainty of the total GHG emission are livestock parameters (LPA), N emission factors (EFN), crop parameters (CPA) and other $\mathrm{EF}$ and parameters (OPA). Among these, crop parameters (CPA) have a higher contribution in Latin America. Biophysical data (BFD) hardly have any effect on the uncertainty of any GHG, but this can be explained by the use of mainly Tier1 emission factors, where all uncertainty is captured in the emission factor, and not in the underlying explaining biophysical factors.

\section{Discussion and conclusions}

\section{Presenting uncertainty results}

Uncertainty of model inputs, parameters and outputs can be presented in different ways. IPCC (2006) provides guidelines on uncertainty documentation, suggesting that the uncertainty should be reported as the percentage lower and upper bound of the $95 \% \mathrm{CI}$ over the mean. However, literature sources use many different presentation ways and it is not always clear how to interpret the provided information. Monni et al. (2004) presented model output uncertainty as upper bounds of the $95 \% \mathrm{CI}$, expressed as percent relative to the mean value (roughly two times the $\mathrm{SD}$, if normally distributed). Winiwarter and Rypdal (2001) also provide the model output uncertainty as two times the SD over the mean. However, FAO provides the uncertainty as percentage of SD to the mean (i.e. $\mathrm{CV}$ ) in the LCA of GHG emissions from the dairy sector (Gerber et al. 2010), while in the global assessment of emissions and mitigation opportunities (Gerber et al. 2013) the uncertainty is expressed as two times the SD divided by the mean. This difference makes it confusing and difficult to compare results from different studies, especially when the meaning of the presented uncertainty is not stated clearly.

All methods mentioned above have their advantages and disadvantages. The $\mathrm{CV}$, as used in our study, is a widely accepted measure of uncertainty, which can be directly used in an uncertainty calculation. However, a highly skewed distribution is not well characterized by the CV. In this case, a $95 \%$ CI gives more insight into the distribution type. However, using a $95 \% \mathrm{CI}$ also has its disadvantage. The confidence interval usually has to be transformed to a SD or CV in order to perform an uncertainty assessment. In this research, using the $\mathrm{CV}$ to document uncertainty was an appropriate method, since the model output emissions did not have highly skewed distributions.

\section{GHG emissions from livestock predicted by MITERRA-Global}

The results of this study showed that $\mathrm{CH}_{4}$ emissions contribute most to livestock GHG emissions. This is in line with the FAO study of Gerber et al. (2013) using the GLEAM model. Although both studies included comparable major GHG emission sources in feed production and 
Table 8 Comparing GHG emissions from livestock from this study (base year is mean 2007-2009) with Gerber et al. (2013) (base year is 2005)

\begin{tabular}{lllll}
\hline GHG & \multicolumn{2}{l}{$\%$ total GHG emission } & & Gerber et al. (2013) \\
\cline { 2 - 5 } & \multicolumn{2}{l}{ Our study } & & All continents on global scale \\
\cline { 2 - 5 } & Africa & Latin America & EU-27 & 59 \\
\hline $\mathrm{CH}_{4}$ & 63 & 68 & 33 & 29 \\
$\mathrm{~N}_{2} \mathrm{O}$ & 36 & 30 & 8 & 27 \\
$\mathrm{CO}_{2}$ & 1 & 2 & 59
\end{tabular}

${ }^{a}$ Results obtained from FAO report using Global Livestock Environmental Assessment Model (GLEAM; Gerber et al. 2013) livestock production, results from Gerber et al. (2013) showed a much higher contribution from $\mathrm{CO}_{2}$ emissions than our study (Table 8). This is caused by a difference in system boundaries. Gerber et al. (2013) included post-farm gate processes, such as transport of livestock products and manufacture of packaging. These downstream processes are not included in MITERRA-Global. In addition, GHG emission sources due to land use change are not included in MITERRA-Global model, but considered by Gerber et al. (2013). Land use change contributes considerably to the GHG emissions from livestock sectors, but it is a very uncertain source. $\mathrm{CO}_{2}$ emission due to land use change caused by pasture expansion contributes about $15 \%$ to the total GHG emissions from the beef supply chain. For the pig supply chains, $\mathrm{CO}_{2}$ emission from land use change caused by soybean cultivation contributes about $13 \%$ to the total GHG emissions (Gerber et al. 2013).

\section{Uncertainty in GHG emissions estimated by MITERRA-Global}

The total simulated GHG emissions from livestock sectors at continental level showed relatively low uncertainty (12-18\% in terms of CV), although a relatively high uncertainty might occur at country or sector level. A review by Nijdam et al. (2012) of a range of LCA-based studies on livestock products showed a much larger range of carbon footprints from animal food products. However, the data used for the LCAs in Nijdam et al. (2012) ranged from a single farm to complete national industries. In our study, the uncertainty is estimated at continental level while taking spatial correlations into account. The GHG emissions per kilogram products estimated by MITERRAGlobal are in line with the study by Nijdam et al. (2012).

When examining the results of uncertainty in GHG emission of the individual gases, we found that $\mathrm{CO}_{2}$ and $\mathrm{N}_{2} \mathrm{O}$ emissions have a higher uncertainty than the $\mathrm{CH}_{4}$ emissions. Although the relative uncertainty in $\mathrm{CH}_{4}$ emission is much lower than the uncertainty in $\mathrm{CO}_{2}$ emission, the total $\mathrm{CH}_{4}$ emission is much higher than $\mathrm{CO}_{2}$ emission, and therefore the uncertainty contribution of $\mathrm{CH}_{4}$ emission factors (EFC) is higher than the $\mathrm{CO}_{2}$ emission factors (OPA).

Another relevant result is that the uncertainty in GHG emissions in Europe is lower than those in Latin America and Africa. This can be explained by the availability of more country-specific data for Europe, leading to a lower input uncertainty. For the $\mathrm{N}$ excretion factors, the IPCC Tier $1 \mathrm{EFs}$ were used for Latin America and Africa, while for EU-27 country-specific excretion factors from GAINS (Klimont and Brink, 2004) were used (Tier 2 approach). This resulted in a lower uncertainty in $\mathrm{N}_{2} \mathrm{O}$ soil emissions for Europe. Philibert et al. (2012) and Leip (2010) suggested that the ranges of the IPCC $\mathrm{N}_{2} \mathrm{O}$ emission factors might be overestimated with the Tier 1 approach. This implies that our uncertainty estimates for $\mathrm{N}_{2} \mathrm{O}$ emissions in Latin America and Africa could be overestimated. In addition, the uncertainty derived from the statistical data is in general larger in Latin America and Africa than in Europe (see supplementary material, Appendix S2). Some data are also available at a higher spatial resolution (country level) in Europe, and this relatively detailed spatial level reduced the uncertainty for the EU-27 results. Uncertainties in emissions from the ruminant supply chain (beef, caw milk, sheep milk, etc.) are mainly determined by livestock parameters (including $\mathrm{N}$ excretion, manure system usage), $\mathrm{CH}_{4}$ and $\mathrm{N}_{2} \mathrm{O}$ emission factors. For pork, it is mainly caused by livestock parameters and $\mathrm{N}$ emission factors and for eggs and chicken mainly by $\mathrm{N}_{2} \mathrm{O}$ emission factors, livestock parameters, crop parameters and other emission factors. $\mathrm{CH}_{4}$ emission factors do not play an important role for GHG emissions from eggs and chicken.

We also compared the uncertainty quantification results with other studies. Gerber et al. (2013) found for ruminants an uncertainty of 0.25 , and between 0.10 and 0.15 for monogastrics (in terms of $\mathrm{CV}$, values derived from the $95 \%$ CI). In our study, we found $0.12-0.19$ for ruminants and $0.15-0.26$ for monogastrics. The higher uncertainty for monogastrics in our study might be associated with the high uncertainties involved with the $\mathrm{N}_{2} \mathrm{O}$ soil emission and the $\mathrm{CO}_{2}$ emission. In addition, Gerber et al. (2013) only performed their uncertainty assessment for a few selected 
countries. Usually, the uncertainty at country level is higher than at continental level, due to the cancelling out effect of the uncertainty during spatial aggregation (Kros et al. 2012). Use of only a few selected countries might not be representative for the uncertainty at country level in general, as large variation may exist among countries. In another FAO study by Gerber et al. (2010) on the GHG emissions from the dairy sector using a Tier 2 approach, they reported a CV of $0.12-0.13$ for meat and milk, in both Sweden and Nigeria. Our research showed a comparable $\mathrm{CV}$ for meat and milk production for the EU-27: 0.12-0.14 in $\mathrm{EU}$, but higher $\mathrm{CVs}$ for Africa: 0.18-0.19. In MITERRA-Global, a Tier 1 approach is used in Latin America and Africa, while for part of the emissions a Tier 2 approach was applied in the EU-27. The difference between the uncertainty in Nigeria from Gerber et al. (2010) and the uncertainty in Africa from our study indicates that a Tier 2 approach could reduce the uncertainty.

\section{Recommendations for reducing uncertainties}

The focus of our study was on the uncertainty of model inputs and model parameters, while uncertainty in categorical input data and uncertainty due to model structure and model implementation was not considered. Accurate and comprehensive measurement data of emission categories to derive probability distributions are seldom available (Monni et al. 2004). In this research, it was only possible to quantify the uncertainty for input parameters derived from FAO database. The same limitation applies to the correlation and distribution types.

Our research showed that parameter values used for the $\mathrm{CH}_{4}$ and $\mathrm{N}_{2} \mathrm{O}$ emission factors are the main contributors (about 50-60\%) to the uncertainty at continental scale. Improvement of the accuracy of emission factors values might therefore be more effective in reducing the uncertainty in GHG emissions from livestock, rather than putting more effort to improve the activity data. Further implementation of Tier 2 approaches in both modelling and inventory reporting may reduce the uncertainties, especially for Latin America and Africa. However, shifting from a Tier 1 to Tier 2 approach might also require additional activity data. For example, for enteric fermentation a Tier 2 approach requires data on feed intake and feed quality, which might reduce the uncertainty in the emission factor, but might increase the uncertainty in the activity data. Also for a Tier $2 \mathrm{~N}_{2} \mathrm{O}$ emission factor, a shift in uncertainty might occur from the emission factor to activity data and especially the biophysical data, e.g. soil type. The current neglect of this dependency at Tier 1 may lead to an underestimation of the uncertainty contribution of BFD. As discussed before, studies have shown that the uncertainty of Tier 1 emission factors might have been overestimated.
This effect is more prominent when focusing at a higher spatial resolution (see e.g. Leip et al. 2011b). Re-evaluating the uncertainties of these emission factors might also reduce the uncertainty of GHG emissions estimation. Furthermore, development of country- or region-specific emission factors and guidelines on applying current emission factors and their associated uncertainty may further reduce the uncertainty in GHG emissions.

In summary, our work to quantify the uncertainties of the GHG emission profiles of livestock at continental scale showed that the uncertainty is higher in Latin America and Africa than in Europe and that $\mathrm{CH}_{4}$ emission factors and livestock-related parameters, such as $\mathrm{N}$ excretion and manure management, contribute the most to the uncertainty in total GHG emissions from profiles of livestock sectors. The presented analysis of uncertainties of livestock GHG emissions per livestock product and total emissions can be used as guidance for the improvement of national GHG emission inventories, e.g. by improving data collection for certain activity data or country-specific emission factors, especially those that contribute most to the uncertainty.

Acknowledgments The authors gratefully acknowledge the European Commission DG Research for funding this research under the FP7 project ANIMALCHANGE (Grant No. 266018). The research is co-financed by the Dutch Ministry of Economic Affairs (KB-12006.04-003). We thank Dennis Walvoort and Gerard Heuvelink for implementation of algorithms and Peter Kuikman for his critical comments on an early draft of the manuscript.

Open Access This article is distributed under the terms of the Creative Commons Attribution 4.0 International License (http://crea tivecommons.org/licenses/by/4.0/), which permits unrestricted use, distribution, and reproduction in any medium, provided you give appropriate credit to the original author(s) and the source, provide a link to the Creative Commons license, and indicate if changes were made.

\section{References}

Bannink A, Van Schijndel M, Dijkstra J (2011) A model of enteric fermentation in dairy cows to estimate methane emission for the Dutch National Inventory Report using the IPCC Tier 3 approach. Anim Feed Sci Technol 166:603-618. doi:10.1016/j. anifeedsci.2011.04.043

Bellarby J, Tirado R, Leip A, Weiss F, Lesschen JP, Smith P (2013) Livestock greenhouse gas emissions and mitigation potential in Europe. Glob Change Biol 19:3-18. doi:10.1111/j.1365-2486. 2012.02786.x

Biograce (2011) Harmonized calculation of biofuel greenhouse gas emission in Europe. http://www.biograce.net/home. Accessed 3 Sept 2015

Boyer EW, Howarth RW, Galloway JN, Dentener FJ, Green PA, Vörösmarty CJ (2006) Riverine nitrogen export from the continents to the coasts. Glob Biogeochem Cycles 20:GB1016. doi:10.1029/2005GB002537

De Vries M, De Boer I (2010) Comparing environmental impacts for livestock products: a review of life cycle assessments. Livest Sci 128:1-11. doi:10.1016/j.livsci.2009.11.007 
Del Grosso S, Ogle S, Parton W, Breidt F (2010) Estimating uncertainty in $\mathrm{N}_{2} \mathrm{O}$ emissions from US cropland soils. Glob Biogeochem Cycles 24:GB1015. doi:10.1029/2009GB003544

Delgado CL, Rosegrant MW, Steinfeld H, Ehui SK, Courbois C (1999) Livestock to 2020: the next food revolution. IFPRI Food, Agriculture, and the Environment Discussion Paper 28. Washington DC, USA

Dise NB, Ashmore M, Belyazid S, Bleeker A, Bobbink R, De Vries W, Erisman JW, Van den Berg L, Spranger T, Stevens C (2011) Nitrogen as a threat to European terrestrial biodiversity. In: Sutton MA, Howard CM, Erisman JW et al. (eds) The European nitrogen assessment, Chapter 20, Cambridge University Press, Cambridge, pp 463-494

Flugsrud K, Hoem B (2011) Uncertainties in the Norwegian greenhouse gas emission inventory. Statistics Norway, Reports 2011/35 p

Galloway JN, Burke M, Bradford GE, Naylor R, Falcon W, Chapagain AK, Gaskell JC, McCullough E, Mooney HA, Oleson KL (2007) International trade in meat: the tip of the pork chop. AMBIO: A J Hum Environ 36:622-629. doi:10.1579/00447447(2007)36[622:ITIMTT]2.0.CO;2

Gerber P, Vellinga T, Opio C, Henderson B, Steinfeld H (2010) Greenhouse gas emissions from the dairy sector a life cycle assessment. Africa. Food and Agriculture Organization of the United Nations (FAO), Rome

Gerber PJ, Steinfeld H, Henderson B, Mottet A, Opio C, Dijkman J, Falcucci A, Tempio G (2013) Tackling climate change through livestock-a global assessment of emissions and mitigation opportunities. Rome, Food and Agriculture Organization of the United Nations. Food and Agriculture Organization of the United Nations (FAO), Rome

Heuvelink G, Pebesma EJ (1999) Spatial aggregation and soil process modelling. Geoderma 89:47-65. doi:10.1016/S00167061(98)00077-9

IPCC (2006) 2006 IPCC guidelines for national greenhouse gas inventories, prepared by the national greenhouse gas inventories programme. IGES, Kamiyamaguchi

IPCC (2007) Climate change 2007: synthesis report. Contribution of working groups I, II and III to the fourth assessment report of the intergovernmental panel on climate change [Core Writing Team, Pachauri, R.K and Reisinger, A. (eds.)]. IPCC, Geneva, Switzerland, $104 \mathrm{pp}$

Karimi-Zindashty Y, Macdonald J, Desjardins R, Worth D, Hutchinson J, Verge X (2012) Sources of uncertainty in the IPCC Tier 2 Canadian livestock model. J Agric Sci 150:556-569. doi:10. 1017/S002185961100092X

Klimont Z, Brink C (2004) Modelling of emissions of air pollutants and greenhouse gases from agricultural sources in Europe. IIASA IR, 04-048, Laxenburg, Austria

Kros J, Heuvelink GBM, Reinds GJ, Lesschen JP, Ioannidi V, De Vries W (2012) Uncertainties in model predictions of nitrogen fluxes from agro-ecosystems in Europe. Biogeosciences 9:4573-4588. doi:10.5194/bg-9-4573-2012

Leip A (2010) Quantitative quality assessment of the greenhouse gas inventory for agriculture in Europe. Clim Chang 103:245-261. doi:10.1007/s10584-010-9915-5

Leip A, Busto M, Corazza M, Bergamaschi P, Koeble R, Dechow R, Monni S, De Vries W (2011a) Estimation of $\mathrm{N}_{2} \mathrm{O}$ fluxes at the regional scale: data, models, challenges. Curr Opin Environ Sustain 3:328-338. doi:10.1016/j.cosust.2011.07.002

Leip A, Busto M, Winiwarter W (2011b) Developing spatially stratified $\mathrm{N}_{2} \mathrm{O}$ emission factors for Europe. Environ Pollut 159:3223-3232. doi:10.1016/j.envpol.2010.11.024

Lesschen J, Stoorvogel J, Smaling E, Heuvelink G, Veldkamp A (2007) A spatially explicit methodology to quantify soil nutrient balances and their uncertainties at the national level. Nutr Cycl Agroecosyst 78:111-131. doi:10.1007/s10705-006-9078-y
Lesschen J, Van den Berg M, Westhoek H, Witzke H, Oenema O (2011) Greenhouse gas emission profiles of European livestock sectors. Anim Feed Sci Technol 166:16-28. doi:10.1007/s10705-006-9078-y

Lesschen JP, Staritsky I, Oenema O (2014) Improvements in MITERRA framework/tool and the extension to Africa and Latin America. Report AnimalChange (Deliverable 3.5). http:// www.animalchange.eu. Accessed 3 Sept 2015

Limpert E, Stahel WA, Abbt M (2001) Log-normal distributions across the sciences: keys and clues. Bioscience 51:341-352. doi:10.1641/0006-3568(2001)051[0341:LNDATS]2.0.CO;2

MacLeod M, Gerber P, Mottet A, Tempio G, Falcucci A, Opio C, Vellinga T, Henderson B, Steinfeld H (2013) Greenhouse gas emissions from pig and chicken supply chains-a global life cycle assessment. Food and Agriculture Organization of the United Nations (FAO), Rome

Menzi H, Oenema O, Burton C, Shipin O, Gerber P (2010) Impacts of intensive livestock production and manure management on the environment. In: Steinfeld H, Mooney HA, Schneider F, Neville LE (eds) Livestock in a changing landscape, drivers, consequences, and responses, vol 1. Island Press, pp 139-163

Monni S, Syri S, Savolainen I (2004) Uncertainties in the Finnish greenhouse gas emission inventory. Environ Sci Policy 7:87-98. doi:10.1016/j.envsci.2004.01.002

Nijdam D, Rood T, Westhoek H (2012) The price of protein: review of land use and carbon footprints from life cycle assessments of animal food products and their substitutes. Food Policy 37:760-770. doi:10.1016/j.foodpol.2012.08.002

Opio C, Gerber P, Mottet A, Falcucci A, Tempio G, MacLeod M, Vellinga T, Henderson B, Steinfeld H (2013) Greenhouse gas emissions from ruminant supply chains-a global life cycle assessment. Food and Agriculture Organization of the United Nations (FAO), Rome

Philibert A, Loyce C, Makowski D (2012) Quantifying uncertainties in $\mathrm{N}_{2} \mathrm{O}$ emission due to $\mathrm{N}$ fertilizer application in cultivated areas. PLoS ONE 7:e50950. doi:10.1371/journal.pone.0050950

Seitzinger S, Harrison J, Dumont E, Beusen AH, Bouwman A (2005) Sources and delivery of carbon, nitrogen, and phosphorus to the coastal zone: an overview of global nutrient export from watersheds (NEWS) models and their application. Glob Biogeochem Cycles 19:GB4S01. doi:10.1029/2005GB002606

Smaling E, Roscoe R, Lesschen J, Bouwman A, Comunello E (2008) From forest to waste: assessment of the Brazilian soybean chain, using nitrogen as a marker. Agric Ecosyst Environ 128:185-197. doi:10.1016/j.agee.2008.06.005

Smil V (2002) Eating meat: evolution, patterns, and consequences. Popul Dev Rev 28:599-639. doi:10.1111/j.1728-4457.2002.00599.x

Steinfeld H, Gerber P, Wassenaar T, Castel V, Rosales M, De Haan C (2006) Livestock's long shadow: environmental issues and options. Food and Agriculture Organisation of the United Nations(FAO), Rome

Velthof G, Oudendag D, Witzke H, Asman W, Klimont Z, Oenema O (2009) Integrated assessment of nitrogen losses from agriculture in EU-27 using MITERRA-EUROPE. J Environ Qual 38:402-417. doi:10.2134/jeq2008.0108

Weiss F, Leip A (2012) Greenhouse gas emissions from the EU livestock sector: a life cycle assessment carried out with the CAPRI model. Agric Ecosyst Environ 149:124-134. doi:10. 1016/j.agee.2011.12.015

Winiwarter W, Rypdal K (2001) Assessing the uncertainty associated with national greenhouse gas emission inventories: a case study for Austria. Atmos Environ 35:5425-5440. doi:10.1016/S13522310(01)00171-6

Zehetmeier M, Gandorfer M, Hoffmann H, Müller U, De Boer I, Heißenhuber A (2014) The impact of uncertainties on predicted greenhouse gas emissions of dairy cow production systems. J Clean Prod 73:116-124. doi:10.1016/j.jclepro.2013.09.054 